This is the Author's Accepted Manuscript version.

Please cite this article as: Li, Nanya, Li, Yingguang, Hang, Xiang and Gao, James (2014) Analysis and optimization of temperature distribution in carbon fiber reinforced composite materials during microwave curing process. Journal of Materials Processing Technology, 214 (3). pp. 544-550. ISSN 0924-0136 doi:10.1016/j.jmatprotec.2013.10.012

NOTE: This is a PDF file of an unedited manuscript that has been accepted for publication. The manuscript will undergo copyediting, typesetting, and review of the resulting proof before it is published in its final form. Please note that during the production process errors may be discovered which could affect the content, and all legal disclaimers that apply to the journal pertain. 


\title{
Analysis and optimization of temperature distribution in carbon fiber reinforced composite materials during microwave curing process
}

\author{
Nanya $\mathrm{Li}^{\mathrm{a}}$, Yingguang $\mathrm{Li}^{\mathrm{a}}{ }^{*}$, Xiang Hang ${ }^{\mathrm{a}}$, James Gao \\ a College of Mechanical and Electrical Engineering, Nanjing University of Aeronautics and \\ Astronautics, Nanjing, 210016, China \\ b Centre for Innovative Product Development \& Manufacturing, School of Engineering, University of \\ Greenwich, Chatham Maritime, Kent, ME4 4TB, UK
}

\begin{abstract}
Vacuum assisted microwave curing technologies and modified optical sensing systems have been employed to investigate the influence of ply orientation and thickness on through-thickness temperature distribution of carbon fiber reinforced composite laminates. Two different types of epoxy systems have been studied. The results demonstrated that the ply orientation did not affect the temperature distribution of composite materials. However, the thickness was an important influencing factor. Nearly $10^{\circ} \mathrm{C}$ temperature difference was found in $22.5 \mathrm{~mm}$ thick laminates. Through analyzing the physical mechanisms during microwave curing, the temperature difference decreased when the heat-loss in surface laminates was reduced and the absorption of microwave energy in the center laminates was improved. The maximum temperature difference of the samples formed using themodified microwave curing technologies in this research could be reduced by $79 \%$ to $2.1{ }^{\circ} \mathrm{C}$.

Compared with the $5.29{ }^{\circ} \mathrm{C}$ temperature difference of laminates using thermal heating process, the maximum temperature difference in laminates using modified microwave curing technologies was reduced by $60 \%$, and the curing time was cut down by $25 \%$.
\end{abstract}

\footnotetext{
*Corresponding author at: College of Mechanical and Electrical Engineering, Nanjing University of Aeronautics and Astronautics, Nanjing, 210016, China.

Tel.: +8625 84895835; fax: +862584895906.

E-mail address: liyingguang@ nuaa.edu.cn (Yingguang Li).
} 
Key words: microwave curing, composite materials manufacturing, temperature distribution optimisation

\section{Introduction}

Carbon fiber/epoxy composite materials with high mechanical strength, light weight and excellent high-temperature characteristics have gained substantial interest and been widely used in various commercial applications, especially in the aerospace industry. For example, Li et al. (2013) and Shyha et al. (2010) reported that the application of high performance composites increased dramatically in aerospace industry and are expanding.

The huge demand for high performance airplanes have become one of the major forces to drive composite manufacturing technologies. Currently, the conventional thermal heating process of advanced composite laminates with large thickness occurred unacceptable temperature gradients in the thickness direction. Bogetti and Gillespie (1992) reported that the complex gradients of temperature in thickness direction of composite laminates may cause serious process-induced residual stress and deformation.

For the above reason, alternative processing technologies, such as microwave curing technologies have been developed to form composite structures and provide a uniform temperature distribution. Kwak et al. (2011) studied the mechanical properties of [Spell out CFRP here] (CFRP) laminates cured by theVötsch Hephaistos Microwave (VHM) oven, which can provide a homogeneous microwave distribution. The microwave cured samples showed higher mechanical performance than those cured by conventional heating. Liu et al. (2010) reported that microwave curing had no obvious effect on rheological property of polyethylene/carbon black composites. Ku et al. (2001) applied variable frequency microwave facilities to process the 
polymeric materials, which could offer a rapid and uniform heating over a large volume at a high energy coupling efficiency. Thostenson and Chou (1999) discussed the electromagnetic theory and dielectric response of microwave heating for composite materials, and reported that the application of microwave for processing polymer composite materials have more efficient heat transfer over traditional heat transfer method. Thus, microwave curing technologies have been investigated as an efficient energy delivering and uniform heating method to composite materials. Industrial microwave processing is usually accomplished at a few fixed frequencies, such as $915 \mathrm{MHz}, 2.45 \mathrm{GHz}, 5.8 \mathrm{GHz}$ and $24.124 \mathrm{GHz}$. By using the $2.45 \mathrm{GHz}$ frequency microwave, Yarlagadda and Hsu (2004) implemented the differential scanning calorimeter technique to measure the glass transition temperature on both microwave and conventional heating. Their experiment results showed that the epoxy resins cured by microwave have higher glass transition temperature than the conventional heating. Boey and Yap (2001) reported that microwave curing was more effective than conventional heating in enhancing the reaction rates during cross-linking by testing different curing agents in curing.

As discussed above, the $2.45 \mathrm{GHz}$ frequency microwave curing may have advantages in processing the composite parts. But for carbon fiber reinforced composites, Nightingale and Day (2002) reported that the presence of carbon fibers in the composite may affect the penetrating depth of the microwave energy, because of the electrical conductivity and electromagnetic reflection of carbon fiber bundles. The experiments accomplished by Hunyar et al. (2006) also showed that the anisotropic properties of composite materials may affect the temperature distribution. Lee and Springer (1984) developed a computing model to describe the microwave curing process of continuous fiber reinforced composites and reported the carbon fiber may lead to 
problems such as arcing in composites. Until now, the temperature gradient in the thickness direction of carbon fiber reinforced composite materials has still not been measured quantitatively. The influencing factors of temperature distribution also need further research.

In order to measure the temperature during microwave curing, Bond et al. (1999) used a miniature gas thermometer with pressure transducer to indicate the temperature of the materials under microwave field. Yarlagadda and Cheok (1999) and Wei et al. (1991) investigated the effect of the microwave curing of epoxies using an Infra-red thermometer, and compared the glass transition temperature of mould materials using microwave heating and conventional oven heating methods. Rao and Rao (2008) used a thermal imaging camera to measure the temperature distribution of a resin samples cured in a microwave oven. However, those approaches can only measure the surface temperature of composite materials. The temperature inside composite materials could not be measured.

This paper reports on-going work carried out by the authors in the investigation of the through-thickness temperature distribution of carbon fiber reinforced composite laminates influenced by ply orientation and thickness. A multiple mode applicator was used for microwave curing, and vacuum techniques were performed to assist the microwave curing. Fiber Bragg Grating (FBG) sensors were applied in the modified optical sensing system to measure both the surface and center temperature of composite parts during the forming process. Two different types of epoxy systems were studied. The physical mechanisms during microwave curing were analyzed and the microwave curing technologies were modified to provide a uniform temperature distribution. 


\section{The Experiment}

\subsection{Materials Used}

The laminates used in this experiment are T300/6509 and T300/10128 carbon fiber/epoxy unidirectional prepreg. The resin content of both prepreg is $33 \%$. The two materials are typically used for the production of high performance composite structures, such as composite fairing, panels and wind ribs of aircrafts. They respectively represent the average toughness with low glass transition temperature epoxy resins, and high toughness with high glass transition temperature epoxy resins. Other supporting materials are supplied by Airtech Company, such as vacuum bag L500Y, release film Peelplysc01, breather B150 and perforated release film RP3. The thermo-mechanical properties of the epoxy and fiber are given in Table 1, where "E" means tensile modulus, "G" means shear modulus, " $\mu$ " represents Poisson's ratio and " $\alpha$ " represents the coefficient of thermal expansion.

\section{Table 1}

Thermo-mechanical properties of polymer systems.

\begin{tabular}{lllll}
\hline Material & $\mathrm{E} /(\mathrm{GPa})$ & $\mathrm{G} /(\mathrm{GPa})$ & $\mu$ & $\alpha /\left(10^{-6} /{ }^{\circ} \mathrm{C}\right)$ \\
\hline 10128 epoxy & 5.12 & 1.87 & 0.37 & 42.51 \\
6509 epoxy & 4.35 & 1.59 & 0.37 & 43.92 \\
\hline
\end{tabular}

\subsection{Sample Preparation}

The sample composite laminate, with dimensions of $100 \times 100 \mathrm{~mm}$, was produced by hand cutting and lay-up of two types of prepreg. Metal materials are known to reflect microwave energy, thus a tooling suitable for use inside the microwave field is wave-transparent material, such as 
glass and ceramic tooling. A ceramic tooling for use inside the microwave field was manufactured, with low coefficient of thermal expansion and excellent thermal stability.

A particular aspect of the microwave curing technology is the arcing of the carbon fiber bundles. Composite materials may be damaged during arcing. Thus sealant tapes were used to seal the vacuum bag to suppress the arcing between the carbon fibers. It was adhered along the edge of composite materials and compacted using vacuum pressure, as shown in Fig. 1. This setup allowed the microwave processing of composites without arcing and had a better performance. The temperature at the top surface, center and bottom surface of the composite laminates were measured by embedded FBG sensors in the materials. Four FBG sensors were numbered and packaged in a glass capillary to monitor the cure cycle (see Fig. 1).

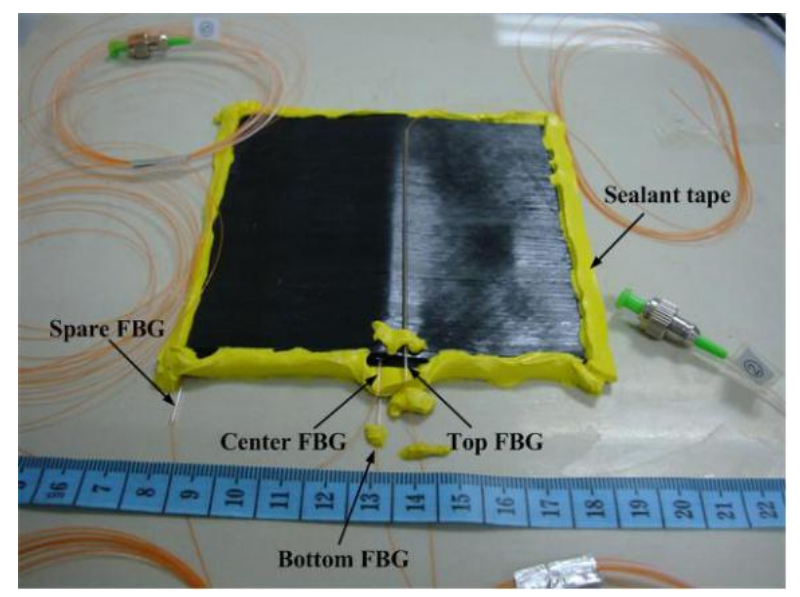

Fig. 1. Sample preparation for the composite curing process

In order to investigate the through-thickness temperature distribution of the composite laminates influenced by ply orientation and thickness, the single factor experiment approaches were taken. Table 2 shows the experimental parameters of ply orientation and thickness. The T300/6509 and T300/10128 composites were both studied in each experiment. For the ply orientation experiment, the samples had the same thickness $(7.5 \mathrm{~mm})$, but with different ply 
orientations. The composite samples prepared for ply thickness experiment had different thickness, but with the same [0/90] ply orientation.

\section{Table 2}

Experimental parameters of ply orientation and thickness

\begin{tabular}{lllll}
\hline Influence factors & Sample \#1 & Sample \#2 & Sample \#3 & Same parameter \\
\hline Ply orientation & {$[0]$} & {$[0 / 90]$} & {$[0 /+45 /-45 / 90]$} & Thickness: $7.5 \mathrm{~mm}$ \\
Ply thickness & $4.5 \mathrm{~mm}$ & $7.5 \mathrm{~mm}$ & $22.5 \mathrm{~mm}$ & Ply orientation : [0/90] \\
\hline
\end{tabular}

\subsection{The Curing Procedure and Devices Used}

A high performance industrial microwave oven (NJL2-1) was custom-modified to accommodate the vacuum pipe and FBG sensors. Two electromagnetic microwave generators have a variable power output of 0 to $1.5 \mathrm{KW}$ at a frequency of $2.45 \mathrm{GHz}$ and are installed at the bottom of the multiple mode applicator. The power of magnetrons can be continuously adjusted. The waveguides of two generators are designed to produce a multiple mode field, which can guarantee a uniform electromagnetic wave distribution. The temperature was measured by an SM125 optical sensing interrogator, and was transferred to the PC through the Internet. The real-time data of microwave power was also transferred to the PC using the universal data transmission interface. The technological process is explained in a schematic diagram, as shown in

Fig. 2. 


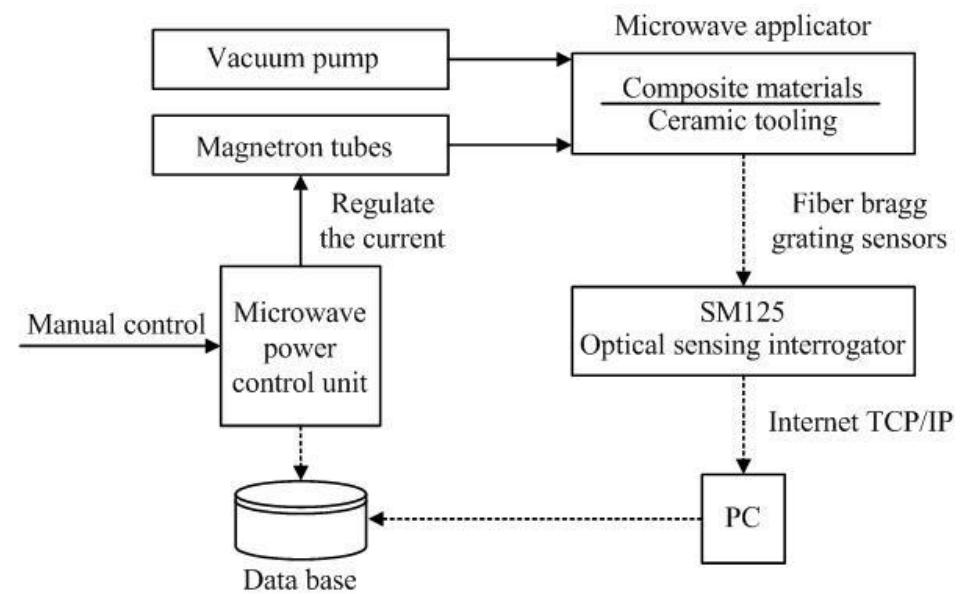

Fig. 2. The microwave curing and temperature measurement method

The out of autoclave (OOA) curing profile of T300/6509 prepreg was set at $90{ }^{\circ} \mathrm{C}$ for 30 minutes then at $120^{\circ} \mathrm{C}$ for 1 hour to ensure the complete curing and then cooling down to room temperature. The curing cycle of T300/10128 was set at $100{ }^{\circ} \mathrm{C}$ for 30 minutes and then the temperature was held at $160{ }^{\circ} \mathrm{C}$ for 1 hour. Shorter curing time to reach the maximum curing percentage was observed in the microwave cured composites than thermally cured composites by Chaowasakoo and Sombatsompop (2007). The microwave curing cycle was set at $90{ }^{\circ} \mathrm{C}$ or $100{ }^{\circ} \mathrm{C}$ for 10 minutes and then heated up to $120^{\circ} \mathrm{C}$ or $160{ }^{\circ} \mathrm{C}$, held for 30 minutes before natural cooling to room temperature. Boey (1992) applied vacuum bags for consolidation, and less void contents were observed in microwave cured composites. Considering the previous work, the $0.09 \mathrm{Mpa}$ vacuum pressure was provided when heating from $100{ }^{\circ} \mathrm{C}$ or $90{ }^{\circ} \mathrm{C}$ to the end of heat preservation.

The vacuum bag and other supporting materials were applied to form the composite samples in a multiple model microwave oven, as shown in Fig.3. The composite laminates were laid up on a ceramic tooling coated with release agent and the edge areas were covered by sealant tapes. Using the vacuum pressure technology and ceramic tooling, the composite samples achieved lower cost in manufacturing and better performance. 


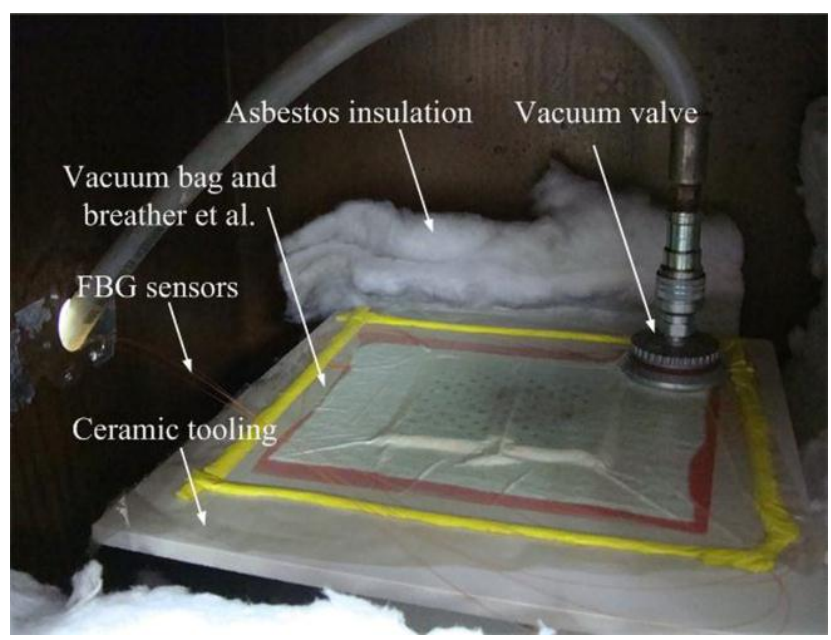

Fig. 3. Vacuum assisted microwave curing process in a multiple model microwave oven.

\subsection{Temperature Measurement}

Electromagnetic wave cannot heat metal materials, but generate electrical current in the metal conduit. This means that conventional metallic thermocouples cannot be used in the microwave heating chamber. Optical sensing interrogator and FBG were used to directly monitor the curing temperature of composite materials. Degamber and Fernando (2003) declared that FBG sensors essentially consist of serious intra-core gratings. A periodic perturbation of the refractive index can be formed along the fiber length through the change of reflection wavelength influenced by the physical or mechanical characteristics of the grating area. Normally, the light travels inside the fiber core and reflects with a center wavelength known as Bragg wavelength. The condition to be satisfied to get such a Bragg reflected wavelength is known as Bragg condition and is given by Grattan and Meggitt (1997) as:

$\lambda_{B}=2 n D$

Where $\lambda_{B}$ is the reflected Bragg wavelength, $n$ is the average refractive index of the fiber core, and $D$ is the grating spacing. The research results by Murukeshan et al. (2000) showed 
that the spacing of the periodic variation of refractive index, which is a function of strain, was elastically deformed with respect to the external strain on the fiber. Therefore, the temperature of a composite part in a microwave oven can be calculated accurately through measuring the movement of center wavelength caused by external thermal strain. Considering the fundamental principles of gratings proposed by Hill and Meltz (1997), the excursion of the wave center can be expressed as:

$\Delta \lambda=\lambda_{B}\left(\left\{1-\frac{n_{e}^{2}}{2}\left[P_{12}-v\left(P_{11}+P_{12}\right)\right]\right\} \Delta \varepsilon+(\alpha+\xi) \Delta T\right)$

Where $\Delta \lambda$ is the excursion of Bragg wavelength, $\Delta T$ is the temperature variation, $\Delta \varepsilon$ is the external strain, $n_{e}$ is the effective index, $v$ is the Poisson ratio, $P_{11}, P_{12}$ and $\xi$ are the constants with respect to the material, and $\alpha$ is the coefficient of thermal expansion. Then the two parts of the explanation can be respectively expressed as:

$$
\begin{aligned}
& P_{\varepsilon}=1-\frac{n_{e}^{2}}{2}\left[P_{12}-v\left(P_{11}+P_{12}\right)\right] \\
& P_{t}=\alpha+\xi
\end{aligned}
$$

Where $P_{\varepsilon}$ is the change rate with strain, $P_{t}$ is the change rate with temperature. Thus, expression (2) can be expressed as:

$$
\Delta \lambda=\lambda_{B}\left(P_{\varepsilon} \Delta \varepsilon+P_{t} \Delta T\right)
$$

In order to measure the temperature variation, the effect of strain $\Delta \varepsilon$ needs to be eliminated by compensating the excursion of Bragg wavelength or modifying the structure of FBG. In this research, a method was proposed to solve this problem. As it can be seen in Fig. 4, a glass capillary is used to pack the FBG. By this means, the Bragg grating will not contact the materials, and the glass capillary has the same physical properties with the FBG sensors. The strain induced 
by the distortion of composite part would not affect the accuracy of temperature measurement. At the same time, the FBG sensors are recyclable after the curing process.

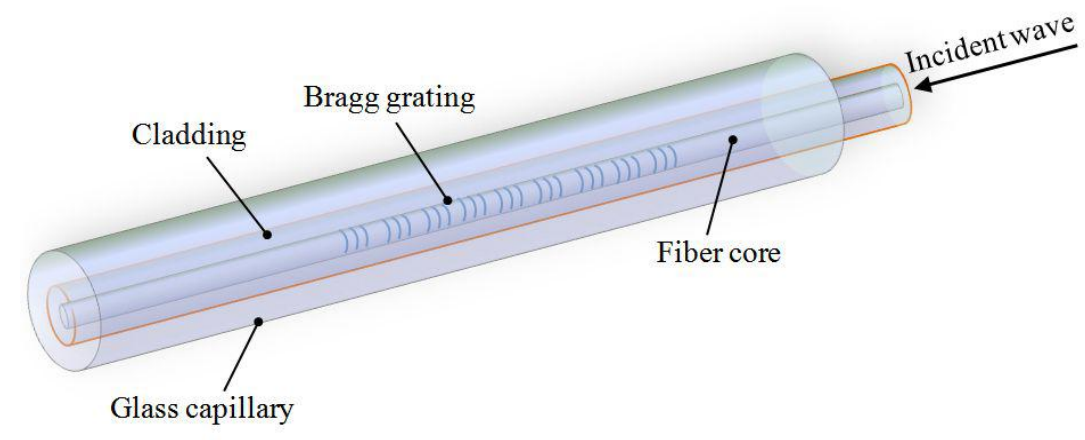

Fig.4. A FBG sensor packed by glass capillary

\section{Results and Discussion}

To verify whether the measuring approach mentioned above would affect the temperature distribution, a non-contact Infrared thermometer was used to measure the temperature at the surfaces of composite materials. One composite sample had 8 layers with a glass capillary packed FBG on its top surface. Another one had no FBG. Two samples were heated in the same experimental conditions. The temperatures at the surfaces of the two samples were measured by modified FBG and Infra-red thermometer. Temperature differences of the measured results of the two samples were within $0.6 \pm 0.1^{\circ} \mathrm{C}$. After eliminating the measuring error, the two temperature values were almost the same. This means that the modified FBG measuring approach is effective and does not affect the temperature distribution of carbon fiber reinforced composites.

Due to the complexity and immaturity of microwave curing process, the appropriate process parameters need to be investigated to guarantee the reliability of experimental results. A representative temperature profile of a composite sample measured by FBG sensors in the thickness direction is shown in Fig. 5. The appropriate heating rate for this sample at two different 
heating-up periods is $1.8^{\circ} \mathrm{C} \mathrm{s}^{-1}$. Other process parameters are also marked in the graph. The top temperature value measured by FBG sensor is marked in red, center is blue and bottom is green.

The relationship between microwave power and curing temperature is also exhibited in the graph.

As revealed in this profile, the heat release of curing reaction is not obvious and three temperature values in the heating-up periods and cooling-down process are almost equal to each other. The large temperature differences were measured during dwell stages (i.e., certain temperature was set and kept constant for a period). Meanwhile, the epoxy resin was consolidated around the two dwell stages. The most important dwell stages were studied to analysis the temperature distribution influenced by ply orientation and thickness.

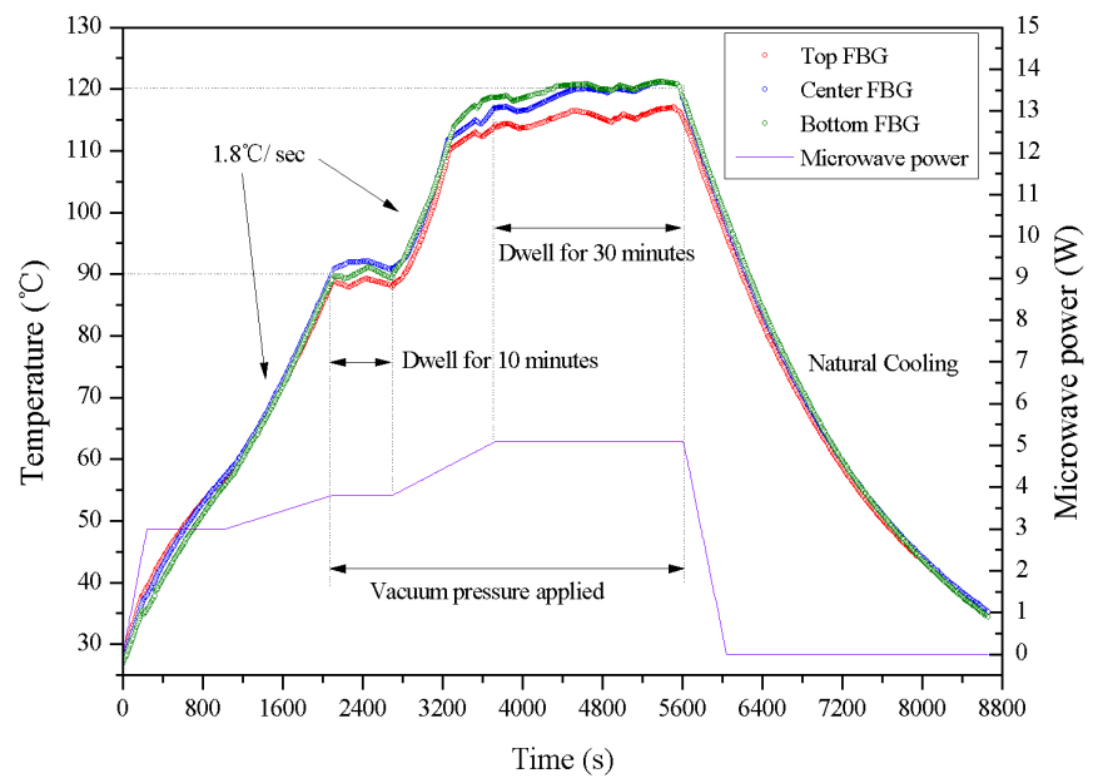

Fig.5. Curing profile of a composite sample during microwave processing

\subsection{Temperature Distribution Influenced by Ply Orientation}

Through employing the verified process parameters mentioned above, the temperature distribution of carbon fiber reinforced composite laminates influenced by ply orientation was investigated. The statistical temperature values of T300/6509 and T300/10128 materials 
influenced by ply orientation with standard deviation are shown in Fig.6. The samples of this experiment provide the same thickness $(7.5 \mathrm{~mm})$, but different ply orientation. Sample \#1, sample $\# 2$ and sample \#3 respectively indicate the [0], [0/90] and [0/+45/-45/90] plied composite laminates. The temperatures of carbon fiber reinforced composite materials are contrastively classified by FBG sensors and compared with target temperatures. The statistical results are designated in the top of every column.

With regards to the T300/6509 composite materials, the maximum temperature difference between statistical results and target temperature values are almost the same, which are shown in Fig. 6 (a) and (b). In detail, the surface temperature of three composite samples is lower than the target value, but the center and bottom temperature are above the target value about $2{ }^{\circ} \mathrm{C}$. The temperature difference in the same measuring position of three samples, which have diverse ply orientations, is within $0.5^{\circ} \mathrm{C}$. The T300/10128 composite materials also get a lower surface temperature, compared with the statistical results as shown in Fig. 6(c) and (d). The center and bottom temperatures are higher than the target temperature. The bottom temperature of three laminate samples provided a nearly $4{ }^{\circ} \mathrm{C}$ temperature gradient to the surface temperature. 


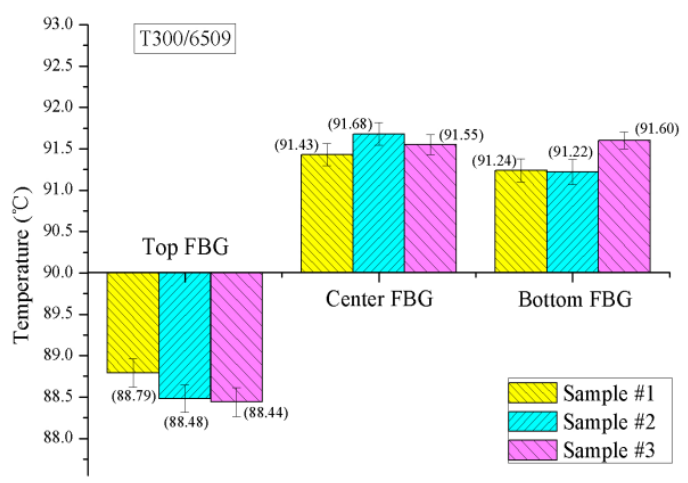

(a)

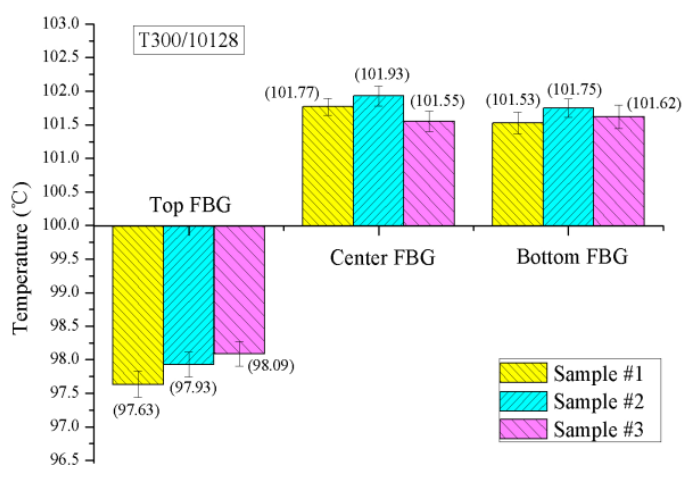

(c)

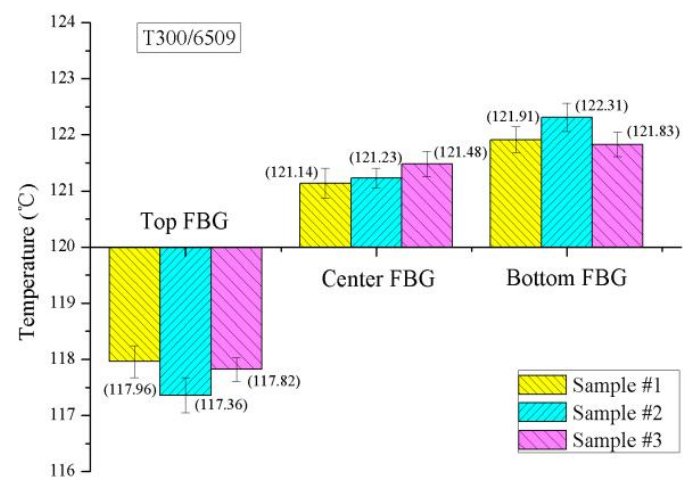

(b)

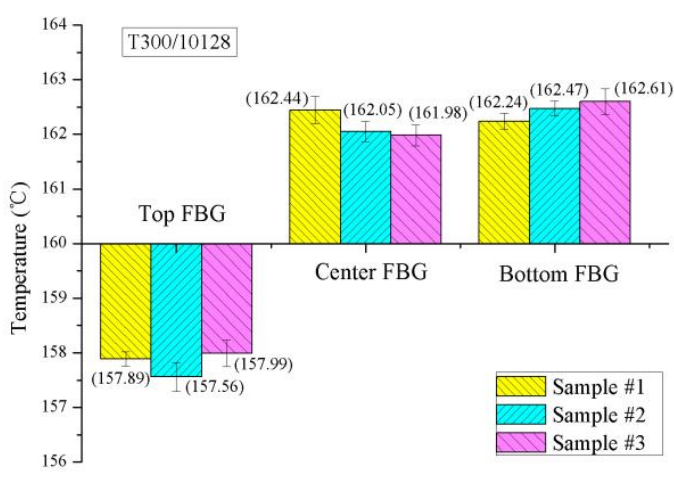

(d)

Fig.6. Statistical temperature difference influenced by ply orientation with standard deviation: (a) temperature difference at $90^{\circ} \mathrm{C}$ holding period of T300/6509, (b) temperature difference at $120^{\circ} \mathrm{C}$ holding period of T300/6509, (c) temperature difference at $100^{\circ} \mathrm{C}$ holding period of T300/10128 and (d) temperature difference at $160^{\circ} \mathrm{C}$ holding period of $\mathrm{T} 300 / 10128$.

As discussed above, the temperature values of the two types of composite materials have exactly the same variation tendency. The surface temperature is generally inferior to the target value, the center and bottom temperature are higher than the target temperature. It can also be concluded from the statistical results that two types of composite materials, and three samples of typical ply forms, have almost the same temperature distribution. The complex [0/+45/-45/90] ply orientation samples have the temperature values close to the [0] lay-up composite laminates. This means that the different ply orientation of carbon fiber reinforced composite laminates would not 
influence the temperature distribution and can be formed well by microwave curing.

\subsection{Temperature Distribution Influenced by Ply Thickness}

Apart from the influence of ply orientation, the influence of ply thickness is also considered in this research. The stacking sequence of three samples is [0/90]. The thickness values of composite laminates are 4.5, 7.5 and 22.5mm, corresponding to sample \#1, sample \#2 and sample \#3 respectively. The statistical results of temperature values of T300/6509 and T300/10128 materials influenced by thickness with standard deviation are shown in Fig.7. The temperatures at two holding periods are contrastively divided by the positions, and compared with target temperature.

Fig. 7 exhibits the measured temperature values of T300/6509 material at $90{ }^{\circ} \mathrm{C}$ and $120{ }^{\circ} \mathrm{C}$ holding periods and T300/10128 material at $100{ }^{\circ} \mathrm{C}$ and $160{ }^{\circ} \mathrm{C}$ dwell temperature. The measured surface temperatures of three samples are lower than that of the middle and bottom, just as the experiment results shown in Fig.6. The temperature of sample \#3 measured by bottom FBG sensors are evidently higher than the other two samples by nearly $2{ }^{\circ} \mathrm{C}$ in both $\mathrm{T} 300 / 6509$ and T300/10128 material. With the increase of thickness, the temperature difference of samples between observed temperatures and target temperatures are increased. Almost $10{ }^{\circ} \mathrm{C}$ temperature difference between the surface and bottom fields is found in sample \#3 (22.5mm thickness). 


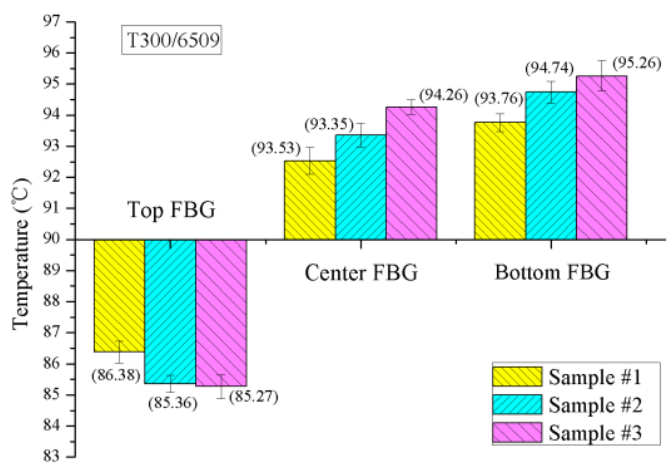

(a)

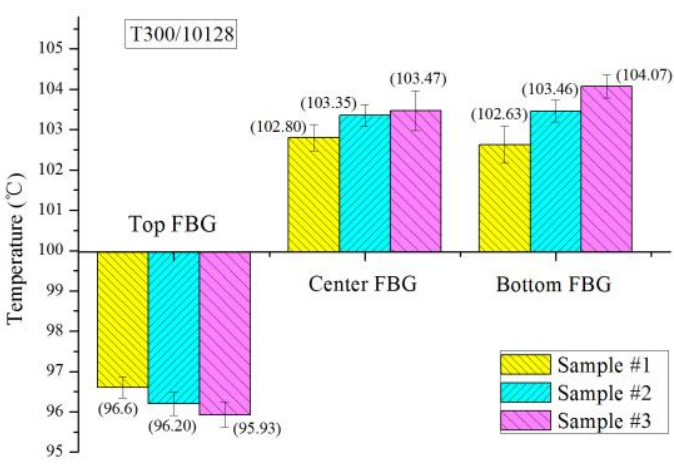

(c)

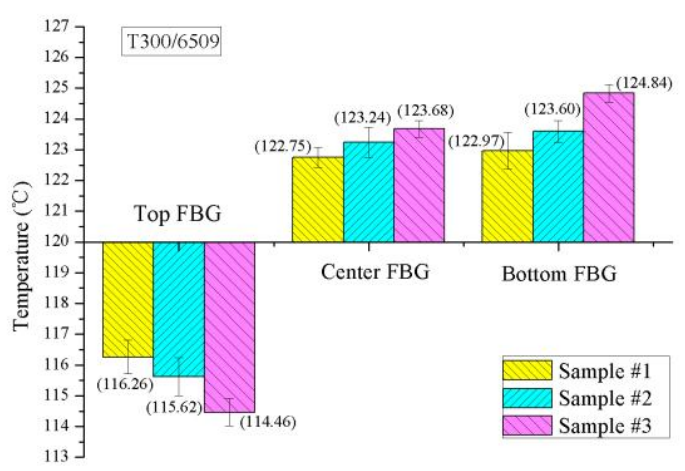

(b)

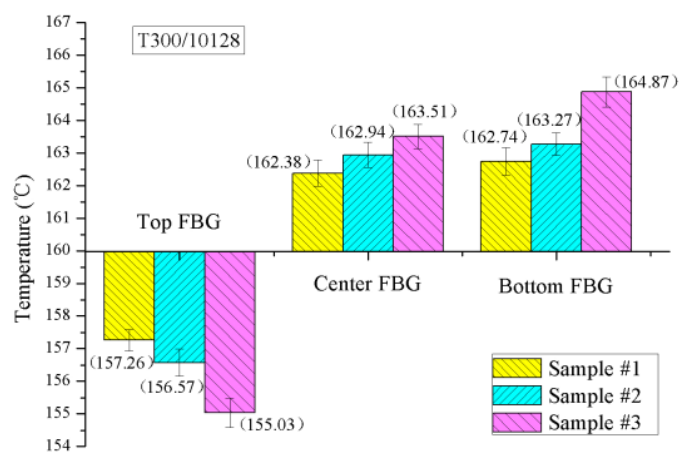

(d)

Fig.7. Statistical temperature difference influenced by thickness with standard deviation: (a)

temperature difference at $90^{\circ} \mathrm{C}$ holding period of T300/6509, (b) temperature difference at $120^{\circ} \mathrm{C}$ holding period of T300/6509, (c) temperature difference at $100^{\circ} \mathrm{C}$ holding period of T300/10128 and (d) temperature difference at $160^{\circ} \mathrm{C}$ holding period of $\mathrm{T} 300 / 10128$.

Experimental results show that, the surface temperatures of three samples are lower than the target value. The temperatures in the top, center and bottom fields are influenced by ply thickness and the temperature in the centre is lower than the temperature in the bottom area. This phenomenon indicates that the microwave energy can penetrate into large-thickness $(22.5 \mathrm{~mm})$ composite laminates. However, the thickness of composite laminate has a remarkable impact on the temperature. The obvious temperature difference in composite laminates may impair the advantages of microwave curing technology. The optimisation methods will be discussed later in 
this article.

\section{Temperature Distribution Analysis and Optimization}

Under the action of an electromagnetic field, the temperature at the surface of carbon fiber reinforced composites is lower than the target temperature, no matter for what kinds of composite laminates. Meanwhile, the experimental results demonstrated that the ply orientation cannot affect the temperature distribution of composites. But the thickness is an important influencing factor. Although the microwave can penetrate into very thick composite laminates, the temperature difference in the thickness direction of carbon fiber reinforced composites is significant.

The physical mechanism of microwave curing includes the natural heat convection of air in the microwave oven, heat conduction inside the composite material and the directly heating action of microwave. Because the air in the microwave oven is still, the natural heat convection can be simplified as heat conduction between the composite material and the air. Thus, the physical models, which influence the temperature distribution, are heat conduction and microwave heating.

Since the microwave curing is a volume-heating technology and the air around the composite materials will not be heated, the temperature of air in the microwave oven is always lower than that of the composite materials. As the composite surface has a large contact area with the air and the carbon fiber bundles are good conductors of heat, the heat conduction primarily happens at the top surface of the composite laminate. Therefore, the surface temperature is lower in the whole curing process. Although the microwave can penetrate into very thick composite laminates, the temperature difference between the center and bottom of the laminates shows that the microwave energy which penetrates into materials decreases layer by layers.

Based on the analysis, in order to uniform the temperature distribution of composite 
laminates, different solutions need to be applied. The surface area should be isolated with the air to slow down the heat transfer, thus a thermal insulation material (wave-transparent) was placed on the top of the composite materials. To reduce the temperature difference between the center and bottom of the laminates, the microwave energy need to penetrate into the materials from both the top and the bottom sides. A supporting magnetron was installed on the top of the microwave oven to generate a microwave in the up-bottom direction. The modified microwave curing technology is shown in Fig.8. The modified portions are marked in red and the blue arrows indicates the direction of propagation of microwave.

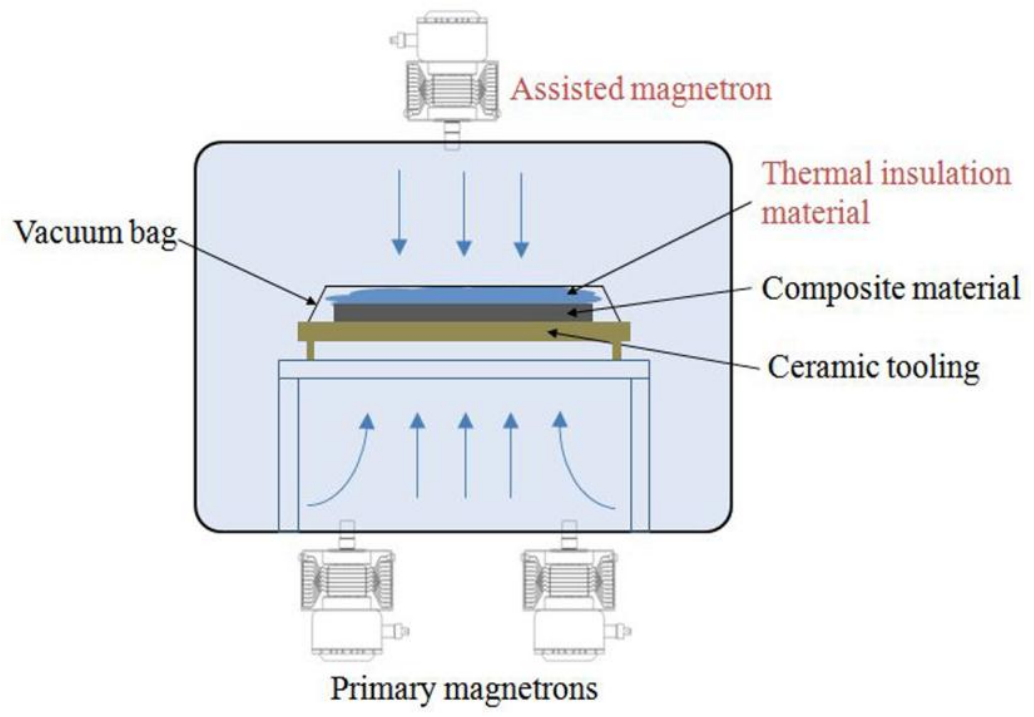

Fig.8. The modified microwave curing technologies.

Experiments were carried out to verify the effectiveness of modified microwave curing technologies. The T300/6509 and T300/10128 composite samples, with [0/90] ply orientation and 150 layers $(22.5 \mathrm{~mm})$ were processed by thermal heating and microwave curing technologies described in this section. The statistical results of temperature differences of three curing technologies are shown in Table 3. The temperature differences were calculated by employing the 
measured temperature to subtract the target values of dwell stages in the same experimental condition.

\section{Table 3}

The temperature differences of three curing technologies.

\begin{tabular}{ccccc}
\hline Different curing technologies & Top $/\left({ }^{\circ} \mathrm{C}\right)$ & Center $/\left({ }^{\circ} \mathrm{C}\right)$ & Bottom $/\left({ }^{\circ} \mathrm{C}\right)$ & $\begin{array}{c}\text { Maximum temperature } \\
\text { difference } /\left({ }^{\circ} \mathrm{C}\right)\end{array}$ \\
\hline Thermal curing & 1.57 & 6.86 & 3.44 & 5.29 \\
Previous microwave curing & -4.97 & 2.51 & 4.87 & 9.84 \\
Modified microwave curing & -0.24 & 0.66 & 1.86 & 2.10 \\
\hline
\end{tabular}

The temperatures at the top and center areas of the samples processed by modified microwave curing technologies were significantly increased, showing a small temperature difference compared with that of the bottom area. The maximum temperature difference was reduced by $79 \%$, compared with the established microwave curing technologies used in the previous research work. Compared with the $5.29{ }^{\circ} \mathrm{C}$ temperature difference of thermal heating process, the maximum difference of carbon fiber reinforced composites was reduced by $60 \%$. The curing time of microwave curing was also cut down by $25 \%$.

\section{Conclusions}

In order to reduce the no-uniformity of temperature distribution in the thickness direction of carbon fiber reinforced composites, vacuum assisted microwave processing technologies and modified optical sensing systems were applied to the study of this problem.

The statistical results of temperature values of T300/6509 and T300/10128 composite laminates demonstrated that the ply orientation did not affect the temperature distribution of composites. However, the thickness was an important influencing factor. According to the 
experimental results, the physical mechanisms during microwave curing were analyzed and the vacuum assisted microwave curing technologies were modified to optimize the temperature distribution. As a result, he even temperature distribution in the thickness-direction of carbon fiber reinforced composite was achieved using modified microwave processing technologies. The whole curing time was also reduced.

This research is an important exploration of the high-performance and thick composite materials processed by microwave technologies used in the aerospace industry. Future studies will be carried out to identify the relationship between several physical mechanisms in microwave curing to get a better temperature distribution and establish the standard process specifications.

\section{Acknowledgements}

This research project is jointly supported by the "Outstanding Talents Cultivation Fund" of Nanjing University of Aeronautics and Astronautics (NE2012003) and the National Natural Science Foundation of China (Grant NO. 51305195). The authors sincerely appreciate the continuous support provided by our industrial collaborators and all those took part in the industrial investigation.

\section{References}

Bogetti, T.A., Gillespie, J.W., 1992. Process-induced stress and deformation in thick-section thermoset composite laminates. Journal of Composite Materials 26, 626-660.

Boey, F., Yap, B., 2001. Microwave curing of an epoxy-amine system: effect of curing agent on the glass-transition temperature. Polymer testing 20, 837-845.

Bond, G., Moyes, R., Pollington, S., Whan, D., 1999. Measurement of temperature during microwave heating (chemical reactions enhancement). Measurement Science and Technology 2, 571-572.

Boey, F.Y., 1992. Effect of moisture content on the high pressure microwave curing of a thermoset 
fiber reinforced composite, the American Chemical Society Spring Meeting 66, 422-423.

Chaowasakoo, T., Sombatsompop, N., 2007. Mechanical and morphological properties of fly ash/epoxy composites using conventional thermal and microwave curing methods.

Composites Science and Technology 67, 2282-2291.

Degamber, B., Fernando, G., 2003. Fiber optic sensors for noncontact process monitoring in a microwave environment. Journal of applied polymer science 89, 3868-3873.

Grattan, L., Meggitt, B., 1997. Optical fiber sensor technology: volume 2: devices and technology. Chapman \& Hall, London, pp. 22-23.

Hunyar, C., Feher, L., Thumm, M., 2006. Processing of carbon-fiber reinforced composite (CFRP) materials with innovative millimeter-wave technology, Advances in Microwave and Radio Frequency Processing, 735-744.

Hill, K.O., Meltz, G., 1997. Fiber Bragg grating technology fundamentals and overview. Journal of Lightwave Technology 15, 1263-1276.

Ku, H.S., Siu, F., Siores, E., Ball, J.A., Blicblau, A., 2001. Applications of fixed and variable frequency microwave (VFM) facilities in polymeric materials processing and joining. Journal of Materials Processing Technology 113, 184-188.

Kwak, M., Robinson, P., Bismarck, A., Wise, R., Middlesbrough, U., 2011. Curing of composite materials using the recently developed hephaistos microwave. In:18th international conference on composite materials, 21-26 August 2011, Korea, pp. 1-6.

Li, Y.G., Li, N.Y., Gao, J., 2013.Tooling Design and Microwave Curing Technologies for the Manufacturing of Fiber-reinforced Polymer Composites in Aerospace Applications. The International Journal of Advanced Manufacturing Technology. doi: 10.1007/s00170013-5268-3

Liu, F., Qian, X., Wu, X., Guo, C., Lei, Y., Zhang, J., 2010. The response of carbon black filled high-density polyethylene to microwave processing. Journal of Materials Processing Technology 210, 1991-1996.

Lee, W.I., Springer, G.S., 1984. Microwave curing of composites. Journal of Composite Materials $18,387-409$.

Murukeshan, V., Chan, P., Ong, L., Seah, L., 2000. Cure monitoring of smart composites using fiber Bragg grating based embedded sensors. Sensors and Actuators A: Physical 79, 153-161.

Nightingale, C., Day, R., 2002. Flexural and interlaminar shear strength properties of carbon fiber/epoxy composites cured thermally and with microwave radiation. Composites Part A: Applied Science and Manufacturing 33, 1021-1030.

Rao, S., Rao, R., 2008. Cure studies on bifunctional epoxy matrices using a domestic microwave oven. Polymer testing 27, 645-652.

Shyha, I., Soo, S.L., Aspinwall, D., Bradley, S., 2010. Effect of laminate configuration and feed rate on cutting performance when drilling holes in carbon fiber reinforced plastic composites. Journal of Materials Processing Technology 210, 1023-1034.

Thostenson, E., Chou T.W., 1999. Microwave processing: fundamentals and applications. Composites Part A: Applied Science and Manufacturing 30, 1055-1071.

Wei, J., Hawley, M.C., Jow, J., DeLong, J., 1991. Microwave processing of crossply continuous graphite fiber/epoxy composites. SAMPE Journal 27, 33-39. 
Yarlagadda, K., Hsu, S.-H., 2004. Experimental studies on comparison of microwave curing and thermal curing of epoxy resins used for alternative mould materials. Journal of Materials Processing Technology 155, 1532-1538.

Yarlagadda, P.K., Cheok, E., 1999. Study on the microwave curing of adhesive joints using a temperature-controlled feedback system. Journal of Materials Processing Technology 91, 128-149. 


\section{Figure and Table Captions}

Fig. 1. Sample preparation for the composite curing process.

Fig. 2. The microwave curing and temperature measurement method.

Fig. 3. Vacuum bagging assisted microwave curing process in a multiple model microwave oven.

Fig. 4. A FBG sensor packed by glass capillary.

Fig. 5. Curing profile of a composite sample during microwave processing.

Fig. 6. Statistical temperature difference influenced by ply orientation with standard deviation: (a) temperature difference at $90^{\circ} \mathrm{C}$ holding period of $\mathrm{T} 300 / 6509$, (b) temperature difference at $120^{\circ} \mathrm{C}$ holding period of T300/6509, (c) temperature difference at $100^{\circ} \mathrm{C}$ holding period of $\mathrm{T} 300 / 10128$ and (d) temperature difference at $160^{\circ} \mathrm{C}$ holding period of $\mathrm{T} 300 / 10128$.

Fig. 7. Statistical temperature difference influenced by thickness with standard deviation: (a) temperature difference at $90^{\circ} \mathrm{C}$ holding period of T300/6509, (b) temperature difference at $120^{\circ} \mathrm{C}$ holding period of $\mathrm{T} 300 / 6509$, (c) temperature difference at $100^{\circ} \mathrm{C}$ holding period of $\mathrm{T} 300 / 10128$ and (d) temperature difference at $160^{\circ} \mathrm{C}$ holding period of $\mathrm{T} 300 / 10128$.

Fig. 8. The modified microwave curing technologies.

\section{Table 1}

Thermo-mechanical properties of polymer systems.

\section{Table 2}

Experimental parameters of ply orientation and thickness.

\section{Table 3}

Comparison of temperature differences of three curing technologies. 